\title{
ANALISIS FAKTOR-FAKTOR YANG MEMPENGARUHI PRODUKTIVITAS TENAGA KERJA PANEN KELAPA SAWIT DI KEBUN BATEE PUTEH PT. AGRO SINERGI NUSANTARA
}

\author{
(Analysis of Factors Affecting the Productivity of Coconut Palm Oil Workers at Kebun \\ Batee Puteh PT. Agro Sinergi Nusantara)
}

\author{
Arham $^{1}$, Azhar ${ }^{1}$, Edy Marsudi ${ }^{*}$ \\ ${ }^{1}$ Program Studi Agribisnis, Fakultas Pertanian, Universitas Syiah Kuala
}

\begin{abstract}
Abstrak. Produktivitas tenaga kerja memegang peranan penting pada perusahaan kelapa sawit, penelitian ini bertujuan untuk mengetahui seberapa besar jumlah tanggungan keluarga, pendapatan total rumah tangga, premi, umur dan pengalaman mempengaruhi produktivitas tenaga kerja panen kelapa sawit di Kebun Batee Puteh PT. Agro Sinergi Nusantara (ASN). Penarikan sampel dilakukan dengan metode proportional random sampling dari 7 afdeling di Kebun Batee Puteh PT. ASN dengan jumlah populasi 157 orang diambil 20\% per afdeling jadi total sampel pada penelitian ini berjumlah 32 orang. Teknik analisis yang digunakan pada penelitian ini adalah analisis regresi berganda. Hasil penelitian menunjukkan secara parsial jumlah tanggungan keluarga, pendapatan total rumah tangga dan premi berpengaruh secara signifikan terhadap prosuktivitas tenaga kerja panen kelapa sawit di Kebun Batee Puteh PT. ASN.
\end{abstract}

Kata Kunci : Produktivitas tenaga kerja, jumlah tanggungan keluarga, pendapatan total rumah tangga, premi, umur, pengalaman.

Abstract. Labor productivity plays an important role in palm oil companies, this study aims to find out how big the number of family dependents, total household income, premiums, age and experience affect the productivity of palm oil harvest work in Kebun Batee Puteh PT. Agro Sinergi Nusantara (ASN). Method that used to take sample is proportional random sampling method from 7 afdeling at Kebun Batee Puteh PT. ASN with a population of 157 people taken 20\% each afdeling so the total sample in this study 32 people. The analysis technique used in this research is multiple regression analysis. The results showed partially the number of family dependents, the total income of households and premiums significantly influence the procurement of labor harvest of palm oil in Kebun Batee Puteh PT. ASN.

Keywords : Labor productivity, number of family dependents, total household income, premiums, age, experience.

\section{PENDAHULUAN}

Produktivitas tenaga kerja pemanen kelapa sawit adalah kemampuan tenaga kerja dalam melakukan kegiatan panen, yaitu pemotongan tandan buah matang panen dan pengutipan brondolan, dibandingkan dengan target panen yang telah ditetapkan perusahaan (Pusat Penelitian Kelapa Sawit, 2009). Produktivitas tenaga kerja dalam lingkup perkebunan kelapa sawit dapat diartikan sebagai besarnya jumlah Tandan Buah Segar yang dipanen persatuan waktu (Kg TBS/hari). Ada beberapa faktor yang mempengaruhi produktivitas, yaitu faktor supra-sarana yang meliputi kemampuan manajemen, hubungan industrial dan kebijakan pemerintah. Selain itu, juga ada faktor manusia yang menjadi sangat penting. Produktivitas tenaga kerja manusia tergantung pada kemampuan dan kemauan setiap orang. Dalam hal ini, kemampuan mengacu pada kemampuan fisik serta tingkat Pendidikan, pelatihan, dan pengalaman, sedangkan faktor kemauan mengacu pada etos kerja, mentalitas, dan motivasi.

*Corresponding author: edymarsudi@unsyiah.ac.id 
Tabel 1. Data Produksi Kebun Batee Puteh PT. Agro Sinergi Nusantara (ASN)

\begin{tabular}{clcccc}
\hline \multirow{2}{*}{ No. } & \multicolumn{1}{c}{ URAIAN } & \multicolumn{3}{c}{ TAHUN } & \multirow{2}{*}{$\begin{array}{c}\text { Rata- } \\
\text { Rata }\end{array}$} \\
\cline { 3 - 5 } & & 2014 & 2015 & 2016 & \\
\hline 1 & Produksi (Kg TBS/Thn) & 2.554 .990 & 2.418 .337 & 2.297 .244 & 2.423 .523 \\
2 & $\begin{array}{l}\text { Target Produksi Kelapa Sawit (Kg/Thn) } \\
\text { Target Produktivitas Tenaga Kerja }\end{array}$ & 2.910 .000 & 4.011 .000 & 4.609 .000 & 2.873 .333 \\
3 & & & & \\
& $\begin{array}{l}\text { Pemanen (Kg/Hari) } \\
4\end{array}$ & 675 & 900 & 1.043 & 872 \\
& $\begin{array}{l}\text { Produktivitas Tenaga Kerja Pemanen } \\
\text { (Kg/Hari }\end{array}$ & 863 & 828 & 786 & 825 \\
5 & Persentase realisasi Pemanen & $127 \%$ & $92 \%$ & $75 \%$ & $94 \%$ \\
\hline
\end{tabular}

Sumber : Data Sekunder Diolah September 2016

Dapat dilihat pada tabel 1, PT. ASN pada tahun 2014 menetapkan target produktivitas tenaga kerja pemanen sebesar $675 \mathrm{Kg} / \mathrm{hari}$ dan realisasi dari tenaga kerja pemanen sebesar $863 \mathrm{Kg} / \mathrm{hari}$ dengan persentase realisasi sebesar 127\%. Namun, pada tahun 2015 PT. ASN menaikkan target produktivitas tenaga kerja panen sebesar 900 $\mathrm{Kg} / \mathrm{hari}$ dengan realisasi sebesar 828 ton/hari dan persentase realisasi 92\%, dan ini merupakan penurunan produktivitas dengan pemanen tidak mencapai target, begitu juga pada tahun 2016, PT. ASN meningkatkan target produktivitas sebesar $1.043 \mathrm{Kg} / \mathrm{hari}$ dengan produktivitas $786 \mathrm{Kg} / \mathrm{hari}$ dan persentase realisasi $75 \%$. Target produktivitas yang ditargetkan perusahaan berdasarkan dari kegiatan sensus panen yang dilaksanakan oleh petugas dengan asumsi perawatan berjalan dengan normal dan pohon kelapa sawit semakin mendekati pada fase puncak produksi.

Perusahaan perkebunan kelapa sawit menetapkan suatu standar pokok ataupun basis panen yang dibuat untuk memenuhi produksi yang ditetapkan dalam Rencana Kerja dan Anggaran Perusahaan (RKAP). Namun, dalam realisasi masih mengalami naik turunnya produksi yang didapat para buruh panen. Seperti pada gambar 1 realisasi dari tenaga kerja panen mengalami penurunan sedangkan target produktivitas perusahaan terus meningkat setiap tahunnya, tentu ini mempengaruhi produksi keseluruhan perusahaan yang menginginkan produksi maksimal. Naik turunnya produktivitas buruh panen dipengaruhi oleh beberapa faktor yang berbeda tiap-tiap pemanen. Dari uraian latar belakang yang menjadi tujuan dari penelitian ini adalah untuk mengetahui seberapa besar pengaruh faktor jumlah tanggungan, pendapatan total rumah tangga, premi, umur dan pengalaman berpengaruh terhadap produktivitas tenaga kerja panen di Kebun Batee Puteh PT. Agro Sinergi Nusantara.

\section{METODE PENELITIAN}

\section{Lokasi dan Waktu Penelitian}

Penelitian ini dilakukan di PT. Agro Sinergi Nusantara yang berlokasi di Meulaboh Aceh Barat. Penentuan lokasi ini ditentukan secara sengaja (purposive) dengan pertimbangan bahwa daerah tersebut merupakan salah satu penghasil komoditi sawit di 
Aceh dan perkebunan besar milik negara terdekat dengan peneliti. Penelitian dilakukan pada bulan Desember.

\section{Objek dan Ruang Lingkup Penelitian}

Objek dalam penelitian ini adalah tenaga kerja panen TBS kelapa sawit yang bekerja di PT. Agro Sinergi Nusantara. Ruang lingkup penelitian mencakup umur, pengalaman, jumlah tanggungan, pengalaman dan premi tenaga kerja panen.

\section{Sumber dan Metode Pengumpulan Data}

Data yang digunakan dalam penelitian ini adalah data primer dan data sekunder. Data primer adalah data yang diperoleh melalui wawancara dengan tenaga kerja panen secara langsung dengan menggunakan kuisioner sedangkan data sekunder diperoleh dari PT. Agro Sinergi Nusantara, instansi terkait dan studi kepustakaan. Data tersebut nantinya digunakan dalam pengujian dan analisa dalam penelitian ini.

\section{Faktor-Faktor Yang Mempengaruhi Produktivitas Tenaga Kerja Panen Kelapa Sawit}

Model analisis yang digunakan dalam pengujian hipotesis adalah: "Regresi Linier Berganda", untuk menganalisis pengaruh beberapa faktor terhadap produktivitas tenaga kerja panen. Penggunaan model ini dimaksudkan untuk menghitung dan menganalisis besarnya pengaruh nilai variabel yang diturunkan terhadap jumlah TBS yang dipanen (Y), dengan demikian model matematisnya sebagai berikut:

$$
\mathrm{Y}=\mathrm{a}_{0}+\mathrm{a}_{1} \mathrm{X}_{1}+\mathrm{a}_{2} \mathrm{X}_{2}+\mathrm{a}_{3} \mathrm{X}_{3}+\mathrm{a}_{4} \mathrm{X}_{4}+\mathrm{a}_{5} \mathrm{X}_{5}+\mathrm{e} \quad \text { (Sugiyono,2014) }
$$

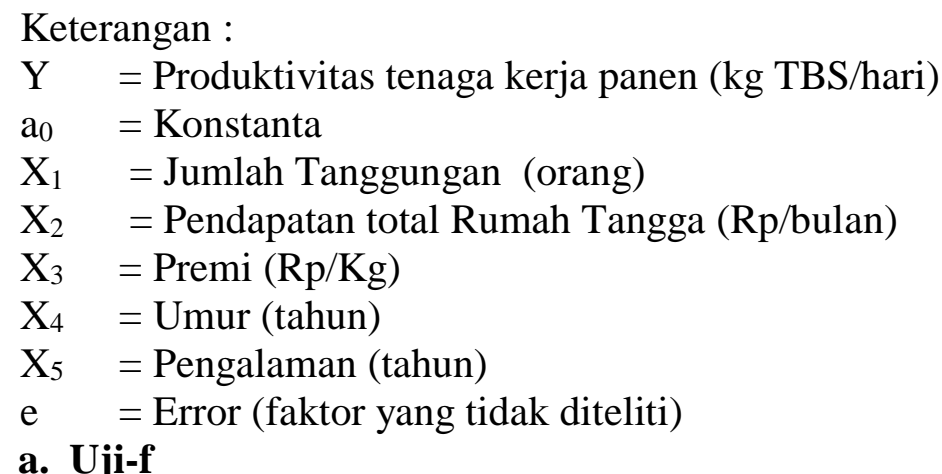

Untuk mengetahui pengaruh secara serempak antar variabel bebas $\left(\mathrm{X}_{1}, \mathrm{X}_{2}, \mathrm{X}_{3}, \mathrm{X}_{4}, \mathrm{X}_{5}\right)$ terhadap variabel terikat $(Y)$ pada taraf nyata $(\alpha=0.05)$ Diuji dengan menggunakan uji $F$ dengan menggunakan rumus sebagai berikut:

$$
\mathrm{F}_{\text {cari }}=\frac{R^{2} / \mathrm{k}}{\left(1-R^{2}\right) /(n-k-1)} \quad(\text { Sudjana, 2002) }
$$

Keterangan:

$\mathrm{R}^{2} \quad=$ Koefisien determinasi

$\mathrm{K} \quad$ = jumlah variabel bebas

$\mathrm{n} \quad=$ jumlah sampel

Hipotesis:

Ho $=$ Produktivitas secara serempak tidak berpengaruh secara signifikan terhadap jumlah tanggungan, pendapatan total rumah tangga, premi, umur dan pengalaman. 
$\mathrm{Ha}=$ Produktivitas secara serempak berpengaruh secara signifikan terhadap jumlah tanggungan, pendapatan total rumah tangga, premi, umur dan pengalaman.

\section{b. Uji-t}

Untuk mengetahui pengaruh secara parsial, yaitu untuk menguji keeratan hubungan antara sebagian dan sejumlah variabel apabila variabel dengan variabel yang lain dianggap tetap. Diuji dengan menggunakan uji " $t$ " dengan menggunakan rumus:

$$
\mathrm{t}_{\text {cari }}=\frac{\left|a_{i}\right|}{S E_{n i}} \quad(\text { Sudjana, 2002) }
$$

keterangan:

$\mathrm{a}_{\mathrm{i}} \quad=$ Koefisien regresi ke- $\mathrm{i}$

$\mathrm{SE}_{\mathrm{ni}}=$ Standar Error ke-1

Hipotesis:

Ho = Produktivitas secara parsial tidak berpengaruh secara signifikan terhadap jumlah tanggungan, pendapatan total rumah tangga, premi, umur dan pengalaman.

$\mathrm{Ha}=$ Produktivitas secara parsial berpengaruh secara signifikan terhadap jumlah tanggungan, pendapatan total rumah tangga, premi, umur dan pengalaman.

\section{c. Uji Koefisien Determinasi $\left(\mathbf{R}^{2}\right)$}

Koefisien determinasi menunjukkan seberapa besar persentase variasi dalam variabel dependen yang dapat dijelaskan dalam variabel independen. Nilai $R$ square terletak antara 0 dan 1 . Jika $\mathrm{R}^{2}$ semakin mendekati 1 maka semakin besar variasi dalam variabel independen. Hal ini berarti semakin tepat garis regresi tersebut mewakili hasil penelitian yang sebenarnya. Koefisien determinasi pada intinya mengukur seberapa jauh kemampuan model dalam menerangkanvariabel bebas $(\mathrm{X})$ terhadap variabel terikat $(\mathrm{Y})$. Untuk menguji koefisien determinasi $\mathrm{R}^{2}$ maka dapat digunakan rumus sebagi berikut:

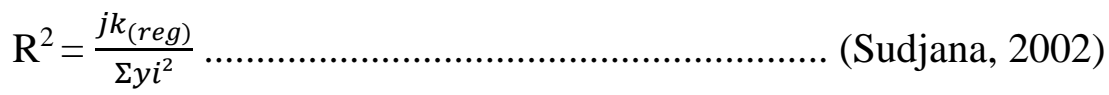

Dimana :

$j k_{(r e g)}=$ Jumlah kuadrat regresi

$\Sigma y i^{2}=$ Jumlah kuadrat total

\section{HASIL DAN PEMBAHASAN}

Analisis Faktor-Faktor Yang Mempengaruhi Produktivitas Tenaga Kerja Panen Kelapa Sawit

Pengujian Hipotesis (Uji t, uji F dan $\mathbf{R}^{2}$ )

Hasil Pengolahan menggunakan SPSS dalam mengetahui faktor-faktor yang mempengaruhi produktivitas tenaga kerja panen kelapa sawit di Kebun Batee Puteh PT. Agro Sinergi Nusantara. 
Tabel 2. Hasil Analisis Faktor-Faktor yang Mempengaruhi Produktivitas Tenaga Kerja Panen Kelapa Sawit di Kebun Batee Puteh PT. Agro Sinergi Nusantara

\begin{tabular}{llll}
\hline \multicolumn{1}{c}{ Model } & \multicolumn{1}{c}{ B } & Std. Error & \multicolumn{1}{c}{ Beta } \\
\hline Konstanta (a) & 160.182 & 41.242 & \\
Jumlah tanggungan keluarga $\left(\mathrm{X}_{1}\right)$ & 146.522 & 20.927 & .697 \\
Pendapatan Total Rumah Tangga $\left(\mathrm{X}_{2}\right)$ & -38.982 & 11.956 & -.206 \\
Premi $\left(\mathrm{X}_{3}\right)$ & 46.146 & 16.150 & .276 \\
Umur $\left(\mathrm{X}_{4}\right)$ & -16.361 & 11.268 & -.104 \\
Pengalaman $\left(\mathrm{X}_{5}\right)$ & 1.972 & 3.048 & .048 \\
\hline
\end{tabular}

Berdasarkan tabel diatas maka persamaan analisis regresi berganda ditulis sebagai berikut: $160,182+146,522 \mathrm{X}_{1}-38,982 \mathrm{X}_{2}+46,146 \mathrm{X}_{3}-16,361 \mathrm{X}_{4}+1,972 \mathrm{X}_{5}+\mathrm{e}$.

Dapat dilihat dari persamaan regresi berganda diatas dapat disimpulkan bahwa koefisien yang bernilai positif pengalaman $\left(\mathrm{X}_{2}\right)$, jumlah tanggungan $\left(\mathrm{X}_{3}\right)$, dan premi $\left(\mathrm{X}_{5}\right)$. Nilai koefisien yang positif artinya, setiap penambahan pengalaman, jumlah tanggungan dan premi produktivitas tenaga kerja panen kelapa sawit di Kebun Batee Puteh PT. ASN akan meningkat atau berbanding lurus dengan koefisien dari hasil analisis regresi. Sedangkan koefisien yang bernilai negative umur $\left(\mathrm{X}_{1}\right)$ dan pendapatan total rumah tangga $\left(\mathrm{X}_{4}\right)$, apabila terjadi penambahan umur dan pendapatan total rumah tangga, maka produktivitas tenaga kerja panen di Kebun Batee Puteh PT. Agro Sinergi Nusantara akan menurun.

\section{Pengujian Hipotesis Uji f}

Pengujian secara serempak dilakukan untuk melihat pengaruh bersama-sama variabel bebas pada penelitian ini dengan variabel terikat. Dalam penelitian ini uji f untuk melihat variabel umur, pengalaman, jumlah tanggungan keluarga, pendapatan total dan premi berpengaruh secara nyata terhadap variabel produktivitas tenaga kerja panen. Berdasarkan hasil analisis menggunakan IBM SPSS 24 diperoleh hasil F hitung sebesar 49,346 dengan nilai signifikansi sebesar 0,000. Nilai signifikasi $0,000<$ taraf signifikasi sebesar 0.05 dan nilai $F$ hitung 49,596> dari $F$ tabel 2,73. Oleh karena itu, dapat disimpulkan terima $\mathrm{H}_{\mathrm{a}}$ dan tolak $\mathrm{H}_{0}$, artinya variabel umur, pengalaman, jumlah tanggungan keluarga, pendapatan total rumah tangga dan premi secara serempak berpengaruh signifikan terhadap produktivitas tenaga kerja panen.

\section{Pengujian Hipotesis Uji t}

Pengujian secara parsial atau uji t dilakukan untuk melihat pengaruh dari variabel bebas terhadap variabel terikat. Uji $t$ dapat dilakukan dengan melihat nilai $t$ hitung atau dengan melihat dari nilai signifikasi hasil analisis. Uji t dilakukan untuk melihat apakah variabel umur, pengalaman, jumlah tanggungan, pendapatan total rumah tangga dan premi secara parsial berpengaruh atau tidak terhadap produktivitas tenaga kerja panen kelapa sawit di Kebun Batee Puteh PT. Agro Sinergi Nusantara.

Untuk melihat hasil pengujian secara parsial dapat dilihat melalui hasil analisis regresi berganda menggunakan IBM SPSS 24 sebagai berikut: 
Tabel 3. Hasil Analisis t Hitung dan Signifikansi dari Masing-Masing Variabel

\begin{tabular}{lccccc}
\hline \multicolumn{1}{c}{ Model } & B & $\begin{array}{c}\text { Std. } \\
\text { Error }\end{array}$ & Beta & T & Sig. \\
\hline Konstanta (a) & 160.182 & 41.242 & & 3.884 & .001 \\
$\begin{array}{l}\text { Jumlah tanggungan keluarga } \\
\left(\mathrm{X}_{1}\right)\end{array}$ & 146.522 & 20.927 & .697 & 7.002 & .000 \\
$\begin{array}{l}\text { Pendapatan Total Rumah } \\
\text { Tangga }\left(\mathrm{X}_{2}\right)\end{array}$ & -38.982 & 11.956 & -.206 & -3.260 & .003 \\
$\begin{array}{l}\text { Premi }\left(\mathrm{X}_{3}\right) \\
\text { Umur }\left(\mathrm{X}_{4}\right)\end{array}$ & 46.146 & 16.150 & .276 & 2.857 & .008 \\
Pengalaman $\left(\mathrm{X}_{5}\right)$ & -16.361 & 11.268 & -.104 & -1.452 & .158 \\
& 1.972 & 3.048 & .048 & .647 & .523 \\
\hline
\end{tabular}

Data primer diolah desember 2017

Berdasarkan tabel diatas dapat dilihat nilai signifikasi dari masing-masing variabel. Terdapat tiga variabel yang nilai signifikansinya lebih kecil daripada 0,05 yaitu variabel jumlah tanggungan, pendapatan total rumah tangga dan premi. Terdapat juga dua variabel yang nilai signifikansinya lebih besar daripada taraf signifikansi yaitu 0,05 , yaitu variabel umur dan pangalaman. Penjelasan lebih lanjut tentang masing-masing pengaruh dari variabel bebas dengan variabel terikat sebagai berikut:

\section{a. Pengaruh Jumlah Tanggungan $\left(\mathrm{X}_{1}\right)$ Terhadap Prduktivitas Tenaga Kerja Panen $(\mathrm{Y})$}

Hasil analisis regresi berganda, koefisien dari jumlah tanggungan keluarga sebesar 146,552, artinya jumlah tanggungan keluarga berbanding lurus dengan produktivitas tenaga kerja panen di Kebun Batee Puteh PT. Agro Sinergi Nusantara. Dengan bertambahnya jumlah tanggungan keluarga 1 orang, maka produktivitas tenaga kerja panen meningkat sebesar 146,552 Kg/Hk, dengan asumsi variabel lain dianggap tetap..

Hasil analisis regresi linier berganda menghasilkan t hitung untuk variabel jumlah tanggungan keluarga sebesar 7,002, dengan t tabel sebesar 2,05 dan nilai signifikansi dari variabel jumlah tanggungan keluarga sebesar 0,000 dan taraf signifikansi 0.05. Dapat disimpulkan $\mathrm{t}$ hitung 7,002 > t tabel 2,05 dan signifikansi $0,000<$ taraf signifikan 0,05 artinya terima $\mathrm{Ha}$ dan tolak H0. Berarti variabel jumlah tanggungan keluarga secara parsial berpengaruh secara signifikan terhadap produktivitas tenaga kerja panen di Kebun Batee Puteh PT. Agro Sinergi Nusantara.

Penelitian di Kebun Batee Puteh PT. ASN mendapatkan hasil bahwa rata-rata jumlah tanggungan keluarga 2-3 orang. Jumlah tanggungan yang ditanggung tenaga kerja panen harus dipenuhi kebutuhan sehari-hari, oleh karena itu tenaga kerja panen yang memiliki jumlah tanggungan yang makin banyak cenderung bekerja lebih giat untuk mendapatkan pendapatan yang mencukupi kebutuhan serta meningkatkan kesejahteraan keluarga. Kata salah seorang tenaga kerja panen " anggota keluarga di rumah merupakan 
motivasi untuk bekerja lebih rajin dan memanen sebanyak mungkin, suapaya mendapatkan premi yang banyak" (MW, 52 tahun dengan jumlah tanggungan 5).

b. Pengaruh Pendapatan Total Rumah Tangga $\left(\mathrm{X}_{2}\right)$ Terhadap Produktivitas Tenaga Kerja Panen (Y)

Hasil analisis regresi linier berganda menghasilkan nilai koefisien dari variabel pendapatan total rumah tangga sebesar $-38,982$ artinya pendapatan total rumah tangga berbanding terbalik dengan produktivitas tenaga kerja panen di Kebun Batee Puteh PT. Agro Sinergi Nusantara. Setiap penambahan pendapatan rumah tangga, maka produktivitas tenaga kerja panen kelapa sawit akan mengurangi produktivitas sebesar $38,982 \mathrm{Kg} / \mathrm{Hk}$, dengan asumsi variabel lain dianggap tetap.

Variabel pendapatan total rumah tangga memiliki nilai t hitung sebesar $-3,260$ dengan t tabel 2,05, nilai signifikasi dari variabel pendapatan total rumah tangga sebesar 0,003 dan taraf signifikansi 0,05. Dapat disimpulkan bahwa pendapatan total $\mathrm{t}$ hitung sebesar $-3,260>2,05$ dan nilai signifikansi sebesar $0,003<0,05$, artinya terima Ha dan tolak H0. Variabel pendapatan total rumah tangga secara parsial berpengaruh secara signifikan terhadap produktivitas tenaga kerja panen di Kebun Batee Puteh PT. Agro Sinergi Nusantara.

Pendapatan total rumah tangga berbanding terbalik dengan produktivitas tenaga kerja panen kelapa sawit dikarenakan oleh beberapa alasan. Pada saat penelitian dilakukan di Kebun Batee Puteh PT. Agro Sinergi Nusantara tenaga kerja panen yang memiliki jam kerja selama 7 jam, tenaga kerja panen kelapa sawit memiliki usaha lain di luar bekerja sebagai pemanen, ada yang membuka warung, bengkel mobil atau sepeda motor, warung nasi dan menjual gorengan. Beberapa tenaga kerja panen juga memiliki anak yang sudah bekerja membantu memenuhi kebutuhan keluarga, sehingga kepala keluarga yang bekerja sebagai tenaga kerja panen kelapa sawit di Kebun Batee Puteh PT. Agro Sinergi Nusantara dapat mengurangi waktu dia bekerja dalam memanen untuk menikmati hasil dari usahanya, untuk bersenang-senang bersama keluarga dan menjaga kesehatan.

\section{c. Pengaruh Premi $\left(\mathrm{X}_{3}\right)$ Terhadap Produktivitas Tenaga Kerja Panen (Y)}

Berdasarkan hasil analisis regresi linier berganda, variabel premi memiliki nilai koefisien sebesar 46,146, artinya variabel premi berbanding lurus dengan produktivitas tenaga kerja panen kelapa sawit di Kebun Batee Puteh PT. Agro Sinergi Nusantara. Artinya setiap penambahan premi dari perusahaan akan meningkatkan produktivitas tenaga kerja panen sebesar 46,146 Kg/Hk, dengan asumsi variabel lain tetap.

Hasil dari analisis regresi berganda variabel premi mendapatkan nilai t hitung sebesar 2,857 dengan t tabel 2.05 dan nilai signifikansi dari variabel premi sebesar 0,008 dan taraf signifikansi sebesara 0,05. Dapat disimpulkan t hitung variabel premi sebesar 2,857 > t tabel 2,05 dan nilai signifikansi sebesar 0,008 < taraf signifikansi sebesar 0,05, artinya terima $\mathrm{Ha}$ dan tolak $\mathrm{H} 0$. Variabel premi secara parsial berpengaruh secara signifikan terhadap produktivitas tenaga kerja panen kelapa sawit di Kebun Batee Puteh PT. Agro Sinergi Nusantara. 
Variabel premi berpengaruh secara signifikan terhadap produktivitas tenaga kerja panen kelapa sawit dikarenakan premi merupakan sebuah penghargaan atau timbal balik yang diberikan perusahaan kepada tenaga kerja panen yang bekerja lebih dari basis tugas harian yaitu $250 \mathrm{Kg} / \mathrm{Hk}$. Oleh karena itu, tenaga kerja panen akan bekerja dengan semangat untuk mendapat premi yang diberikan perusahaan diluar upahnya, semakin tinggi hasil panen yang didapat setiap hari kerja atau produktivitasnya maka premi yang didapatkan akan semakain besar. Besaran premi yang diberikan oleh PT. Agro Sinergi Nusantara untuk Kebun Batee Puteh yaitu Rp. 60/ Kg TBS, sedangkan untuk berondolan sebesar Rp. 150/Kg berondolan. Namun ada juga sanksi yang akan diberikan apabila tenaga kerja panen tidak memenuhi standar panen yang ditetapkan. Pemberian premi yaitu untuk memotivasi tenaga kerja panen untuk memanen sebanyak-banyaknya untuk membantu perusahaan memenuhi target yang ditetapkan pada RKAP (Rencana Kerja Anggaran Perusahaan).

\section{d. Pengaruh Umur $\left(\mathrm{X}_{4}\right)$ Terhadap Produktivitas Tenaga Kerja Panen (Y)}

Koefisien dari hasil analisis regresi berganda variabel umur bernilai negatif, yaitu $-16,361$, artinya terdapat perbandingan terbalik antara produktivitas tenaga kerja dengan umur. Dengan bertambahnya umur 1 tahun maka produktivitas tenaga kerja panen menurun sebesar $16,361 \mathrm{Kg} / \mathrm{Hk}$, dengan asumsi variabel lain dianggap tetap. Nilai signifikansi dari umur adalah sebesar 0,158, variabel umur nilai signifikansi $0,158>$ taraf signifikansi 0,05 , dan nilai t hitung sebesar $-1,383$, variabel umur dengan t hitung 1,452 $<$ dan $\mathrm{t}$ tabel 2,05 dapat disimpulkan bahwa tolak $\mathrm{H}_{\mathrm{a}}$ dan terima $\mathrm{H}_{0}$. Variabel umur secara parsial tidak berpengaruh signifikan terhadap produktivitas tenaga kerja panen kelapa sawit di Kebun Batee Puteh PT. Agro Sinergi Nusantara.

Berdasarkan hasil analisis regresi linier berganda menunjukkan variabel umur memiliki koefisien negatif yaitu -16,361 dan tidak berpengaruh signifikan secara parsial terhadap produktivitas tenaga kerja panen di Kebun Batee Puteh PT. Agro Sinergi Nusantara. Hal ini disebabkan di lapangan tenaga kerja panen di Kebun Batee Puteh PT. Agro Sinergi Nusantara rata-rata berumur 34 tahun dan usia termuda yang didapat di lapangan berumur 24 tahun dan yang tertua 56 tahun. Umur rata-rata yang terbilang masih muda dengan kemampuan fisik yang lebih kuat dari pada tenaga panen yang lebih tua yang memiliki kekuatan fisik yang lemah. Pihak perusahaan juga tidak menetapkan batasan umur umtuk memanen kelapa sawit, selama dia masih sanggup memanen dan memenuhi basis tugas yaitu $250 \mathrm{Kg} / \mathrm{Hk}$.

\section{e. Pengaruh Pengalaman $\left(\mathrm{X}_{5}\right)$ Terhadap Produktivitas Tenaga Kerja Panen (Y)}

$\mathrm{H}$ Hasil dari analisis regresi berganda variabel pengalaman bernilai positif yaitu 1,972, artinya variabel pengalaman berbanding lurus terhadap produktivitas tenaga kerja panen di Kebun Batee Puteh PT. Agro Sinergi Nusantara. Dengan bertambahnya pengalaman 1 tahun, maka produktivitas tenaga kerja panen kelapa sawit akan meningkat sebesar $1,972 \mathrm{Kg} / \mathrm{Hk}$, dengan asumsi variabel lain dianggap tetap.

Berdasarkan hasil analisis regresi berganda, nilai signifikansi dari variabel pengalaman sebesar 0,523, variabel pengalaman dengan signifikansi sebesar 0,523 > taraf signifikansi 0.05 dan nilai $\mathrm{t}$ hitung $0,647<\mathrm{t}$ tabel 2.05. Dapat disimpulkan bahwa variabel pengalaman tidak berpengaruh secara signifikan terhadap produktivitas tenaga kerja 
panen kelapa sawit di Kebun Batee Puteh PT. Agro Sinergi Nusantara, artinya tolak Ha dan terima H0.

Berdasarkan penelitian yang telah dilakukan di Kebun Batee Puteh PT. Agro Sinergi Nusantara variabel pengalaman tidak berpengaruh secara signifikan dikarenakan tenaga kerja panen di Kebun Batee Puteh PT. Agro Sinergi Nusantara rata-rata pengalaman berada pada 1-5 tahun, dan PT. ASN juga baru beroperasi pada tahun 2011, sebelumnya merupakan PT. Basuah Putra Investasi (PT. BPI) sehingga tenaga kerja panen di Kebun Batee Puteh PT. ASN, lebih banyak tenaga kerja baru yang direkrut oleh PT. ASN, sedangkan hanya beberapa tenaga kerja panen saja yang sudah lama bekerja sebagai pemanen kelapa sawit. Tenaga kerja panen kelapa sawit tidak perlu pengalaman yang terlalu lama, karena memanen kelapa sawit mengandalkan kekuatan fisik dan keterampilan. Dalam penelitian Manurung (2012) di PT. Perkebunan Nusantara IV Sawit Langkat, pengalaman kerja juga tidak berpengaruh nyata terhadap produktivitas tenaga kerja panen kelapa sawit.

\section{Koefisien Determinasi $\left(\mathbf{R}^{2}\right)$}

Koefisien determinasi atau $\mathrm{R}^{2}$ digunakan untuk melihat seberapa besar variabel bebas yaitu umur, pengalaman, jumlah tanggungan keluarga, pendapatan total rumah tangga dan premi mampu menjelaskan variabel terikat yaitu produktivitas tenaga kerja panen. Berdasarkan hasil analisis menggunakan SPSS, nilai koefisien determinasi pada penelitian ini sebesar 0,951 atau 95,1\%. Nilai tersebut berarti 95,1\% produktivitas tenaga kerja panen di Kebun Batee Puteh PT. Agro Sinergi Nusantara dapat dijelaskan oleh variabel bebas yang ada di dalam persamaan regresi berganda yaitu umur, pengalaman, jumlah tanggungan keluarga, pendapatan total rumah tangga dan premi. Sisanya 4,9\% dapat dijelaskan oleh variabel lain yang tidak dimasukkan dalam penelitian ini.

\section{KESIMPULAN DAN SARAN}

\section{Simpulan}

Berdasarkan penelitian yang telah dilakukan, maka dapat diambil kesimpulan se Berdasarkan penelitian yang telah dilakukan, maka dapat diambil kesimpulan adalah hasil dari Uji f menunjukkan variabel umur, pengalaman, jumlah tanggungan, pendapatan total rumah tangga dan premi secara serempak berpengaruh signifikan terhadap produktivitas tenaga kerja panen kelapa sawit di Kebun Batee Puteh PT. Agro Sinergi Nusantara. Nilai dari koefisien determinasi dari penelitian ini adalah $95,1 \%$ artinya variabel jumlah tanggungan keluarga, pendapatan total rumah tangga, premi, umur dan pengalaman dapat menjelaskan faktor-faktor yang mempengaruhi produktivitas tenaga kerja panen kelapa sawit di Kebun Batee Puteh PT. Agro Sinergi Nusantara sebesar 95.1\% dan sisanya dijelaskan oleh faktor lain yang tidak diteliti. Hasil Uji t menunjukkan secara parsial variabel jumlah tanggungan keluarga, pendapatan total rumah tangga dan premi berpengaruh signifikan terhadap produktivitas tenaga kerja panen kelapa sawit di Kebun Batee Buteh PT. Agro Sinergi Nusantara.

\section{Saran}


Berdasarkan penelitian dan kesimpulan diatas, maka saran yang dapat diberikan adalah perlu adanya upaya peningkatan produktivitas tenaga kerja panen agar dapat mencapai target perusahaan dengan cara meningkatkan basis kerja harian dari $250 \mathrm{Kg} / \mathrm{Hk}$ menjadi $400 \mathrm{Kg} / \mathrm{Hk}$ dengan nilai premi juga ditingkatkan. Tujuannya agar tenaga kerja panen lebih termotivasi untuk memanen semaksimal mungkin. Perusahaan juga perlu berusaha meningkatkan kesejahteraan pemanen dengan lebih memperhatikan anggota keluarga tenaga kerja panen melalui pemberian tunjangan keluarga.

\section{DAFTAR PUSTAKA}

Adyguna W. F. 2016. Faktor-Faktoryang Mempengaruhi Produktivitas Tenaga Kerya Pemanen di PT Perkebunan Nusantara VII Unit Kebun Kelapa Sawit Rejosari. Skripsi, Jurusan Agribisnis Fakulttas Pertanian Universitas Lampung. Lampung.

Ahmad, S. 2008. Pengaruh Upah Insentif dan Jaminan Sosial Terhadap Produktivitas Karyawan. Ums. Jogjakarta.

Amron \& Taufik, I. 2009. Analisis Faktor-Faktor yang Berpengaruh Terhadap Produktivitas Tenaga Kerja pada Outlet Telekomunikasi Seluler Kota Makasar. Jurnal Sekolah Tinggi Ilmu Ekonomi Nobel. Indonesia.

Arikunto, S. 2006. Prosedur Penelitian: Suatu Pendekatan Praktik. Rineka Cipta. Jakarta.

Darsono Prawironegoro, DR. 2016. Manajemen SDM Abad 21. Nusantara Consulting. Jakarta.

Ghozali, I. 2002. Aplikasi Analisis Multi Variat dengan Program SPSS. Badan Penerbit Universitas Diponegoro. Semarang.

Hasibuan, M. 2008. Manajemen Sumber Daya Manusia. Bumi Aksara. Jakarta.

Kurniawati, F., Manumono, D., Panjang, S.H. 2008. Kajian sosial ekonomi masyarakat sekitar perkebunan kelapa sawit PTPN III di Kab Labuan Batu Kec. Bilah Hulu Sumatra Utara. Bul Ilmiah INSTIPER.

Lubis, I dan Afifah S, N. 2016. Faktor Penentu Produktivitas Tenaga Kerja Panen Kelapa Sawit, Kalimantan Timur. Bul Agrohorti 4 Fakultas Pertanian. IPB. Bogor.

Manullang. 2008. Dasar-Dasar Manajemen. Ghalia Indonesia. Yogyakarta.

Manurung, S. R. 2012. Faktor-faktor yang mempengaruhi Produktivitas Tenaga Kerja Karyawan Pemanen dan Pemupuk di PT. Perkebunan Nisantara IV. Skripsi. Fakultas Pertanian USU. Sumatera Utara

Nainggolan R. 20012. Faktor-Faktor Yang Mempengaruhi Produktivitas Tenaga Kerja Pemanen Sawit Pada PT. Bio Nusantara Teknologi, Bengkulu. Jurnal AGRISEP Vol.11, Maret 2012. Universitas Bengkulu. 
Nasir, N. 2008. Analisis produktivitas Tenaga kerja Buruh Harian Lepas (BHL) terhadap produktivitas tenaga kerja, Jurusan Ekonomi Pembangunan Fakultas Ekonomi. Unbraw. Malang.

Notoatmodjo, S. 2003. Pendidikan Dan Perilaku Kesehatan. Rineka Cipta. Jakarta.

Nurdin, K. 1996. Hubungan Kerja dan Produktivitas. Jurnal Manajemen Science, NO 33. April.

Panggabean, M. 2002. Manajemen Sumber Daya Manusia. Ghalia Indonesia. Jakarta.

Prawirosentono, Suryadi. 2008. Kebijakan Kinerja Karyawan. BPFE. Yogyakarta.

Priyatno, D. 2009. SPSS Untuk Analisis Korelasi, Regresi dan Miltivariate. Penerbit Gava Media. Yogyakarta.

PT. Perkebunan Nusantara IV. 2014. Laporan Tahunan. Medan. Indonesia.

Pusat Penelitian Kelapa Sawit. 2009. Pedoman Umum Sawit. Medan. Indonesia.

Samuelson, Paul A. dan Willian D. Nordaus.2004. Makro Ekonomi Edisi 14.Alih Bahasa Haris Munandar dkk. PT. Gelora Aksara Pratama. Jakarta.

Salmiah. 2012. Faktor-Faktor yang Mempengaruhi Produktivitas Tenaga Kerja Karyawan pemupuk di PTPN IV. Jurnal Universitas Sumatera Utara Vol 1, No 1. Medan.

Sedarmayanti.2010. Manajemen Sumber Daya Manusia Reformasi Birokrasi dan Manajemen Pegawai Negeri Sipil. PT Refka Aditam. Bandung.

Setiadi, D. 2009. Implementasi E - Procurement untuk Meningkatkan Kinerja Operasional PT. Garuda Indonesia. Mini Paper Sistem Informasi Manajemen. Universitas Lampung. Lampung.

Setiawan. 2010. Ekonometrika. Penerbit Andi. Yogyakarta.

Simanjuntak, Payaman, J. 1998. Pengantar Ekonomi Sumber Daya Manusia. Penerbit FE UI. Jakarta.

Sudjana. 2002. Metode Statistlka, Edisi Keenam. Tarsito.Bandung.

Sugiyono. 2014. Metode Penelitian Kuantitatif Kualitatif dan R\&D. Alfabeta. Bandung.

Sumarsono. S. 2009. Teori dan Kebijakan Publik Ekonomi Sumber Daya Manusia. Graha Ilmu. Yogyakarta.

Sukirno, Sadono. 2005. Mikro Ekonomi Teori Pengantar. Edisi Ketiga. Raja Grafindo Persada. Jakarta. 
Suyastiri, N. M., Vandria, D. 2007. Efektivitas Sistem Premi Potong Buah Terhadap Biaya Panen Buah Kelapa Sawit di PT. Serikat Putra di perkebunan Lubuk Raja Riau. Jurnal Dinamika Sosial Ekonomi 1. Riau.

Tanto, Dewi S. M. 2012. Faktor-faktor yang mempengaruhi prpduktivitas pekerja pada pengerjaan atap baja ringan di perumahan Hills Malang. Jurnal Rekayasa Sipil. Malang.

Van den ban,A.W dan Hakwins, H. 1999. Penyuluhan Pertanian. Kanisius. Yogyakarta.

Widarjono, A. 2009. Ekonometrika Pengantar dan Aplikasinya. Penerbit Ekonosia. Yogyakarta. 